\title{
Transmissivity of a Nonwoven Polypropylene Geotextile Under Suction
}

\begin{abstract}
REFERENCE: Stormont, J. C., Ray, C., and Evans, T. M., "Transmissivity of a Nonwoven Polypropylene Geotextile Under Suction," Geotechnical Testing Journal, GTJODJ, Vol. 24, No. 2, June 2001, pp. 164-171.
\end{abstract}

\begin{abstract}
A permeameter has been developed for measuring in-plane transmissivity of geotextiles under a nearly constant value of suction along its length. The permeameter is capable of imposing gradients in excess of $10 \%$ and normal pressure up to $240 \mathrm{kPa}$, and permits the monitoring of the suctions within the geotextile during testing. To demonstrate the capability of the permeameter, a series of transmissivity measurements were made on a nonwoven polypropylene geotextile subject to different suction heads, normal pressures, and gradients. Transmissivities were up to two orders of magnitude less than the saturated value depending the on the magnitude of the suction head and whether the geotextile was being wetted or dried (hysteresis). Transmissivity values were independent of the gradient for these measurements. Increasing the applied normal pressure decreased the transmissivity at all values of suction head.
\end{abstract}

KEYWORDS: transmissivity, geotextiles, permeameter, unsaturated flow, suction

An important hydrologic property of a geotextile is its transmissivity, which characterizes its ability to transmit water in-plane. Experimental methods have been developed for measuring the transmissivity of geotextiles using either a planar flow (ASTM Test Method for Determining the (In-plane) Flow Rate per Unit Width and Hydraulic Transmissivity of a Geosynthetic Using a Constant Head, D 4716) or radial flow configuration (Koerner 1994) under saturated conditions. Because nonwoven geotextiles are often in contact with unsaturated soils, their unsaturated hydraulic properties, including transmissivity, are of interest. In particular, a new method for draining under unsaturated conditions has been developed that relies upon a nonwoven geotextile to be transmissive under suction (Henry and Stormont 2000; Stormont and Stockton 2000).

Nonwoven geotextiles have relatively large pore sizes compared to most soils, and their hydraulic behavior may be expected to be similar to a coarse soil, i.e., large hydraulic conductivities under saturated conditions and low or nonexistent hydraulic conductivies under most unsaturated conditions. Water retention data for nonwoven geotextiles (Stormont et al. 1997) are consistent with this view. During wetting from an initially dry condition, nonwoven

\footnotetext{
${ }^{1}$ Associate professor, Department of Civil Engineering, University of New Mexico, Albuquerque, NM 87131.

2 Technical support engineer, Leap Software, Inc., P.O. Box 16827, Tampa, FL 33687.

${ }^{3}$ Graduate research assistant, School of Civil and Environmental Engineering, Georgia Institute of Technology, Atlanta, GA 30332.
}

geotextiles remain dry until a critical water entry or breakthrough head is reached, after which they wet rapidly. The breakthrough head represents the transition of a material from a hydraulically nonconductive to a conductive state. Thus, if water in contact with the geotextile is at a suction head in excess of the geotextile's breakthrough head, water will not flow into the geotextile. Breakthrough heads for nonwoven polyester and polypropylene geotextiles estimated from water retention data are less than $50 \mathrm{~mm}$ (Stormont et al. 1997). The water retention characteristics are affected by the condition of the geotextile fibers, in particular whether they have been cleaned to remove any residual surface coating from the manufacturing process or whether soil particles have intruded into the geotextile and reside on the fibers (Henry and Holtz 1997; Stormont and Morris 2000). The water retention behavior of nonwoven geotextiles has been found to be hysteretic: during subsequent drying, the specimens retain more water at a given suction head compared to during wetting.

There have been few previous measurements of the in-plane flow capacity of geotextiles under suction. Zerfass (1986) has shown that once saturated, a geotextile may retain its ability to transmit water in the in-plane direction under suction heads of a few tens of millimeters. This behavior has been referred to as syphoning. These measurements did not explicitly address the role of hysteresis, although it was noted that the flow rate was increased if the specimen was first thoroughly wetted. Zerfass also noted that the flow rate decreased with an increase in normal load on the geotextile. An important shortcoming of these flow measurements was that the suction head varied substantially along the length of the geotextile. Because transmissivity is likely to be a function of suction head, these measured flow rates cannot readily be interpreted in terms of transmissivity.

In this paper, a permeameter that measures in-plane flow through geotextiles under suction is described. Because the permeameter permits the geotextile specimen to be tested under nearly constant suction head over its length, these measurements are interpreted in terms of transmissivity. The test method is described, and a series of measurements on a nonwoven polypropylene geotextile are presented.

\section{Test Principle}

Transmissivity is measured in a permeameter that consists of two water-filled reservoirs connected by a platform (Fig. 1). The geotextile lies on the platform and extends into the reservoirs on both ends. The water level in the reservoirs is at or below the platform. The first stage of the test procedure is to establish a constant suction head in the geotextile. When placed in the permeameter, water will rise in the geotextile due to capillary action. The water 


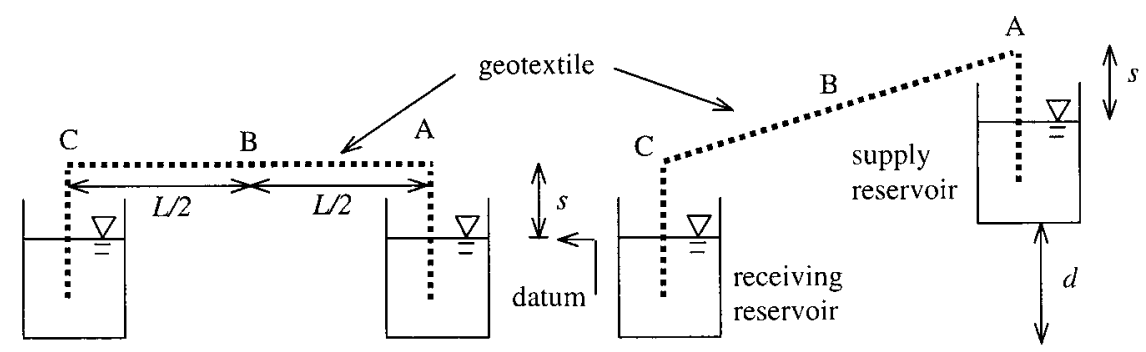

\begin{tabular}{ccccccc}
\hline & \multicolumn{3}{c}{ Stage 1-equilibrium } & \multicolumn{3}{c}{ Stage 2 - flow } \\
\hline location & $\begin{array}{c}\text { suction } \\
\text { head }\end{array}$ & $\begin{array}{c}\text { elevation } \\
\text { head }\end{array}$ & $\begin{array}{c}\text { total } \\
\text { head }\end{array}$ & $\begin{array}{c}\text { suction } \\
\text { head }\end{array}$ & $\begin{array}{c}\text { elevation } \\
\text { head }\end{array}$ & $\begin{array}{c}\text { total } \\
\text { head }\end{array}$ \\
\hline A & s & $\mathrm{s}$ & 0 & $\mathrm{~s}(1+\mathrm{i})$ & $\mathrm{s}+\mathrm{d}$ & $\mathrm{d}-\mathrm{is}$ \\
$\mathrm{B}$ & $\mathrm{s}$ & $\mathrm{s}$ & 0 & $\mathrm{~s}$ & $\mathrm{~s}+1 / 2 \mathrm{~d}$ & $\mathrm{~d}-\mathrm{i}(\mathrm{s}+1 / 2 \mathrm{~L})$ \\
$\mathrm{C}$ & $\mathrm{s}$ & $\mathrm{s}$ & 0 & $\mathrm{~s}(1-\mathrm{i})$ & $\mathrm{s}$ & $\mathrm{d}-\mathrm{i}(\mathrm{s}+\mathrm{L})$ \\
\hline
\end{tabular}

Note: $i=d /(2 s+L)$

FIG. 1-Illustration of test principle and head values at three locations during first the equilibrium and then the flow portion of the test.

that moves into the geotextile will be under a suction head (negative water pressure head) equivalent to the distance it is above the water level in the reservoir. If the distance between the water level and the platform is equal on both sides, then the suction head within the geotextile along the platform length will be uniform.

Once the geotextile is at equilibrium under a given suction head, a total head difference is created between the ends of the geotextile to induce flow. Raising one reservoir relative to the other causes the elevation head and, consequently, the total head on one side of the geotextile to be increased. Flow will be from the raised reservoir (the supply reservoir) to the lower reservoir (the receiving reservoir). Water is added to the supply reservoir and removed from the receiving reservoir so that the water levels in both reservoirs remain constant during the test.

The total, elevation and suction heads at various locations during the two stages of the test are shown in Fig. 1. The total head $H$ is given by

$$
H=z-h
$$

where $z$ is the elevation head (the distance from an arbitrary datum) and $h$ is the suction head (which is the positive-valued equivalent of the water pressure head). When the geotextile has equilibrated at the platform height $s$ (the distance the platform resides above the water level), the suction head at the platform level will be $s$ and the total head will be zero everywhere. In response to raising the supply reservoir a distance $d$, a total head difference of $d$ is induced across the entire length of the geotextile. The hydraulic head gradient $i$ is therefore

$$
i=d /(L+2 s)
$$

where $L$ is the platform length.

The distance between the platform and the water levels in the reservoirs are maintained equal to one another and constant during the test in order to minimize the suction head variation within the geotextile. It is desirable to have the suction head variation as small as possible along the length of the geotextile so that the transmissivity (which is expected to be a function of suction head) is effectively constant. If the transmissivity remains constant along the length of the geotextile, the suction head will vary linearly from $s(1$ $+i$ ) at the supply side of the platform (Point A), $s$ at the middle of the platform (Point $\mathrm{B})$, and $s(1-i)$ at the receiving end of the platform (Point C). If the transmissivity is not constant along the length of the geotextile, then the suction heads would be expected to vary more than that described above.

The steady-state flow rate $Q$ through the geotextile can be used to solve for transmissivity as a function of suction head $\theta\left(h_{m}\right)$ from Darcy's law

$$
\theta\left(h_{m}\right)=Q /(i w)
$$

where $w$ is the width of the geotextile and $h_{m}$ is the mean suction head in the geotextile, which is equal to the platform height $s$. Equation 3 is essentially the same as that used in the reduction of saturated, planar flow transmissivity test data. Implicit in this equation is the assumption that the transmissivity is constant along the length of the geotextile and the transmissivity is independent of the gradient. By conducting a series of measurements at different values of platform height and consequently suction head, transmissivity as a function of suction head can be quantified. Thus, transmissivity under partially saturated conditions is a function of suction and not a single value, whereas it is a constant for saturated flow under positive pressures.

\section{Description of Permeameter}

The permeameter consists of a test box and two water reservoirs (Fig. 2). The steel test box is $308 \mathrm{~mm}$ wide, $92 \mathrm{~mm}$ deep, and 1190 $\mathrm{mm}$ long. Inside the steel box (Fig. 3), the geotextile specimen rests 
on a plexiglas platform ( $20 \mathrm{~mm}$ thick) that is used to house ceramic disks for suction measurements (described below). An inflatable rubber bladder, capable of withstanding pressures up to $240 \mathrm{kPa}$, is located in the bottom of the steel box. A valve from the bladder exits the steel box by means of a small diameter hole, and can be connected to an external source of compressed air to inflate the bladder. An aluminum plate ( $2 \mathrm{~mm}$ thick) is placed between the bladder and the plexiglas to uniformly distribute the pressure exerted by the bladder to the overlying geotextile. A $13 \mathrm{~mm}$ thick aluminum plate is placed on top of the geotextile. Six extruded steel channel sections are located along the length of the box and are bolted together to resist the internal pressure exerted by the bladder. The test box is supported by a four-legged steel telescoping strut and tie system that allows one end of the box to be raised relative to the other.

Both plexiglas water reservoirs are $795 \mathrm{~mm}$ tall, and are $150 \mathrm{~mm}$ by $300 \mathrm{~mm}$ in cross-sectional area. The reservoirs are fitted with lids to limit evaporation. The receiving reservoir has a flexible tube that can be adjusted so that water that enters the reservoir can be drained into a collection flask. The collection flask resides on a scale, permitting direct measurement of the weight of water that has moved through the geotextile and into the receiving reservoir. The water level of the supply reservoir is maintained by manually

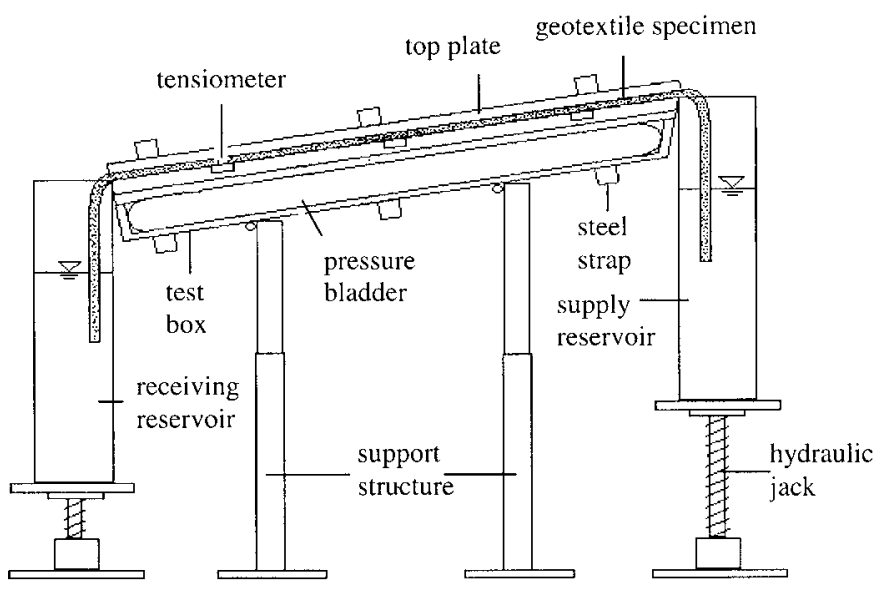

FIG. 2-Schematic of permeameter. adding water. The test box is hinged where it connects to the reservoirs, permitting the reservoirs to be raised relative to one another. The reservoirs rest on hydraulic floor jacks that are used to raise or lower them as required.

The permeameter includes a system for the measurement of suction within the geotextile specimen during transmissivity measurements. Suction head values within the geotextile were useful for two purposes. First, these values can confirm that the geotextile experiences a suction head equivalent to the platform height during the equilibrium portion of the test. Second, the measured suction heads can be used to evaluate the reasonableness of the assumption of constant transmissivity along the length of the geotextile. The plexiglas platform had a series of holes machined into it. The upper $7 \mathrm{~mm}$ of the holes are $29 \mathrm{~mm}$ in diameter into which a porous ceramic disk ( 0.5 bar, high-flow, from Soil Moisture Equipment, Inc.) was fitted so that it is flush with the plexiglas surface. The remaining $6 \mathrm{~mm}$ depth had a diameter of $20 \mathrm{~mm}$. A $6 \mathrm{~mm}$ diameter hole was drilled from the sidewall so that it intercepted the lower portion of the machined hole. The lower portion of the hole and the sidewall hole are filled with water, and provide hydraulic contact with the geotextile through the saturated ceramic disk. The negative water pressure in the sidewall hole, which can be equated to the suction head in the geotextile, was initially measured with a transducer that was connected to the sidewall hole. However, the accuracy of the transducer was insufficient to resolve the small suction head differences of interest in these measurements $(<1 \mathrm{~mm}$ in some cases). An alternative system was used where a flexible tube connected to the sidewall was used as a manometer from which suction heads could be directly read. This system provided a resolution of $\pm 0.5 \mathrm{~mm}$. Most often, only three tensiometers (one near each end and one at the middle of the platform) were monitored because of the time it took to manually make and record these measurements during the transmissivity tests.

\section{Test Procedure}

The permeameter requires a rectangular geotextile specimen with a width equal to that of the platform $(310 \mathrm{~mm})$. The specimen length should be the length of the platform $(1.2 \mathrm{~m})$ plus the length of geotextile that extends into each reservoir. For the measurements reported here with the permeameter shown in Fig. 2, a specimen length of $2.5 \mathrm{~m}$ was used. After the specimen is placed on
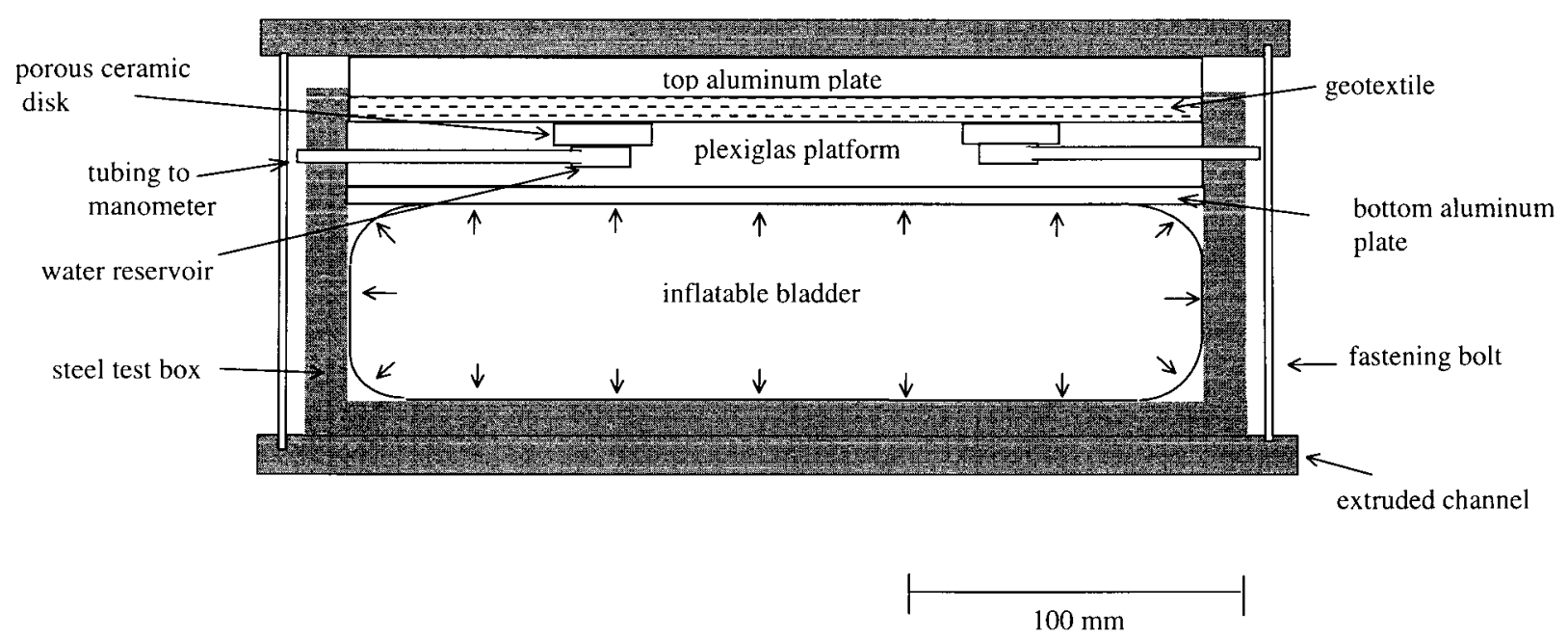

FIG. 3-Cross section through permeameter test box. 
the base of the platform, the lid of the permeameter is secured. The bladder can then be inflated to produce the desired normal pressure on the geotextile.

Water is next added to both reservoirs to achieve the desired initial suction head in the geotextile at the platform level. The value of the initial suction head depends upon the testing objectives. To obtain a complete characterization of the geotextile, the unsaturated transmissivity should be first measured during a wetting path followed by drying because of the anticipated hysteresis in the hydraulic properties. The suction head at which the geotextile first becomes conductive during wetting (the breakthrough head) can be estimated from water retention data (Stormont et al. 1997). Alternatively, the suction head at which the geotextile becomes conductive can be found by beginning the test at a large suction head and progressively decreasing the suction head (i.e., wetting) until the specimen first becomes conductive. Note that any suction head greater than the water entry head can also be used as the initial value, including zero, if only the drying response is desired.

Until the specimen becomes conductive, it was allowed to equilibrate at the imposed suction head for at least $24 \mathrm{~h}$ to ensure water has sufficient time to rise and equilibrate within the geotextile. Henry and Holtz (1997) found little change in capillary rise beyond $24 \mathrm{~h}$ for the nonwoven geotextiles they investigated. Once the specimen became conductive, the equilibrium time was reduced based on the monitored suction heads within the geotextile. As water rises in the specimen, it is necessary to add water to the reservoirs to maintain a constant water level.

At the end of the suction head equilibration period, the hydraulic gradient is created by raising the supply reservoir relative to the receiving reservoir. If no water is collected from the receiving reservoir and no water is required to maintain the supply reservoir level, hydraulic connectivity has not been achieved through the geotextile or the transmissivity is below the measurement system resolution. This latter topic is discussed below.

The amount of water collected from the receiving reservoir outflow is monitored to determine when a steady-state response is achieved. The initial transmissivity of a specimen that is being wetted will be at its minimum value, and the specimen may require substantial time to equilibrate. Once steady-state is achieved, a flow rate through the specimen is measured from the accumulated flow for a period of at least $15 \mathrm{~min}$, and should be repeated at least twice to confirm steady flow is occurring. Temperature is recorded during each measurement interval so that the density variation of water with temperature can be accounted for when converting the measured mass flow rate to volumetric flow rate.

The next value of suction head is imposed on the geotextile specimen by raising or lowering the water level in the reservoir to the desired distance below the platform level. It is preferable to first remove the total head gradient by lowering the supply reservoir. In this way, the permeameter can be left to equilibrate at the new suction head without concern about flow through the geotextile. The procedure for establishing equilibrium and the subsequent transmissivity measurement can then be repeated at this and subsequent values of suction head.

The resolution of the permeameter depends upon the minimum flow rate that can be measured. Over a $24 \mathrm{~h}$ period, the minimum amount of collected water that can be reliably measured is about 10 $\mathrm{g}$, which is equivalent to a volumetric flow rate of about $10^{-1}$ $\mathrm{mm}^{3} / \mathrm{s}$. The transmissivity interpreted from the minimum flow rate depends on the gradient ( $\mathrm{Eq} 3$ ); for the tests reported here, the system resolution varied from about $0.02 \mathrm{~mm}^{2} / \mathrm{s}$ at a gradient of $2.1 \%$ to $0.005 \mathrm{~mm}^{2} / \mathrm{s}$ at a gradient of $8.4 \%$.
Unlike saturated transmissivity measurements, bypass or leakage between the geotextile and the test apparatus is generally not a concern. Under negative water pressures, gaps between the permeameter and the geotextile specimens are nonconductive. Potential bypass leakage is addressed subsequently in the paper.

\section{Description of Geotextile}

Transmissivity measurements were made on a nonwoven polypropylene geotextile; properties as reported by the manufacturer include a thickness of $5.9 \mathrm{~mm}$, an apparent opening size of $0.18 \mathrm{~mm}$, and a mass per unit area of $340 \mathrm{~g} / \mathrm{m}^{2}$. The geotextile's moisture characteristic curve has been measured in a hanging column apparatus (Stormont et al. 1997). In Fig. 4, results are given for suction heads less than $1000 \mathrm{~mm}$ as this is the region over which most of the water content changes occur. The specimens were first tested under a wetting path: beginning air-dry, and progressively decreasing the suction head to zero. The specimen was then dried by progressively increasing the suction head. A nominal surcharge of $0.87 \mathrm{kPa}$ was placed on top of the specimens to limit volume change during the tests. The sharp uptake of water during wetting suggests that the geotextile has a definable water entry suction head in the range of 20 to $40 \mathrm{~mm}$. The water retention data exhibit hysteresis. The water content did not decrease during the initial portions of the drying path, indicating that once wetted, the geotextile may remain relatively wet under small suction heads.

\section{Test Results}

Five series of transmissivity measurements were made on the nonwoven polypropylene geotextile (Table 1). Each series includes numerous transmissivity measurements made following a wetting path, beginning at initial wetting to zero suction head, followed by measurements made during drying until the transmissivity was below the measurement system resolution. Each test series used a separate geotextile specimen taken from the same roll provided by

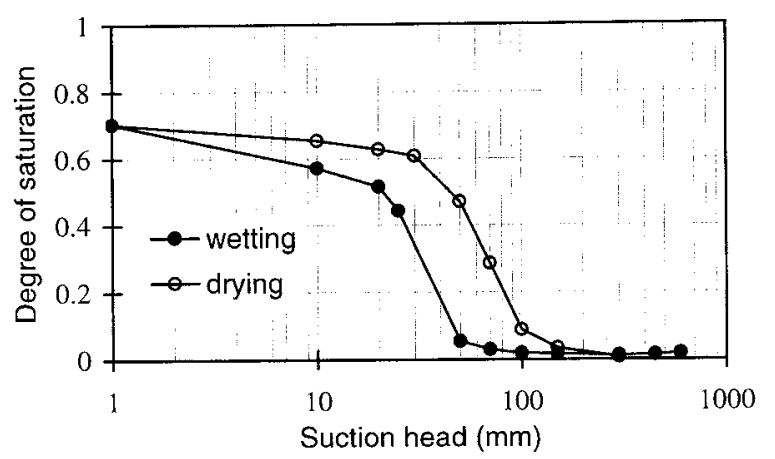

FIG. 4-Water retention data for nonwoven polypropylene geotextile.

TABLE 1-Summary of test series.

\begin{tabular}{cccc}
\hline $\begin{array}{c}\text { Test } \\
\text { Series }\end{array}$ & $\begin{array}{c}\text { Pressure, } \\
\mathrm{kPa}\end{array}$ & Gradient & $\begin{array}{c}\text { Number of } \\
\text { Measurements }\end{array}$ \\
\hline 1 & 0.35 & 0.068 to 0.084 & 22 \\
2 & 69.0 & 0.068 to 0.084 & 17 \\
3 & 34.5 & 0.068 to 0.084 & 16 \\
4 & 34.5 & 0.035 to 0.042 & 14 \\
5 & 34.5 & 0.017 to 0.021 & 14 \\
\hline
\end{tabular}


the manufacturer. The height that the supply reservoir was raised relative to the other end was constant during a test series, but the gradient varied somewhat as the distance above the water level varied between measurements (refer to $\mathrm{Eq} 2$ ). In addition to the five complete test series, a number of limited tests were conducted to address potential bypass leakage and the influence of the platform materials in contact with the geotextile.

The results from the five test series are summarized in Fig. 5. For each test series, both wetting and drying path data were obtained. The suction head at which transmissivity could first be measured on the wetting path is labeled on the figure. At greater values of suction head during wetting, no flow through the geotextile was detected. As the geotextiles were progressively wetted to near zero suction head, the transmissivity increased by about an order of magnitude. During subsequent drying, the geotextiles remain trans- missive to beyond $100 \mathrm{~mm}$, well beyond the suction at which they initially became transmissive. The transmissivities during wetting are lower than those at comparable suctions during drying. The final measurable transmissivity on the drying path is also labeled on the figure. At greater suction heads, there was no detectable flow and thus no measurable transmissivity. Recall that the minimum resolution of the test system was on the order of 0.005 to 0.02 $\mathrm{mm}^{2} / \mathrm{s}$ depending on the gradient and the test duration.

The water retention and transmissivity data are consistent. During wetting, the water retention data indicated that the geotextiles typically did not accept much water until the suction head was reduced to 20 to $40 \mathrm{~mm}$; the geotextiles had an immeasurably low transmissivity until the suction head was reduced to about 20 to 25 $\mathrm{mm}$. The geotextile rapidly takes up water as the suction head is reduced to zero, and coincides with the transmissivity increasing by

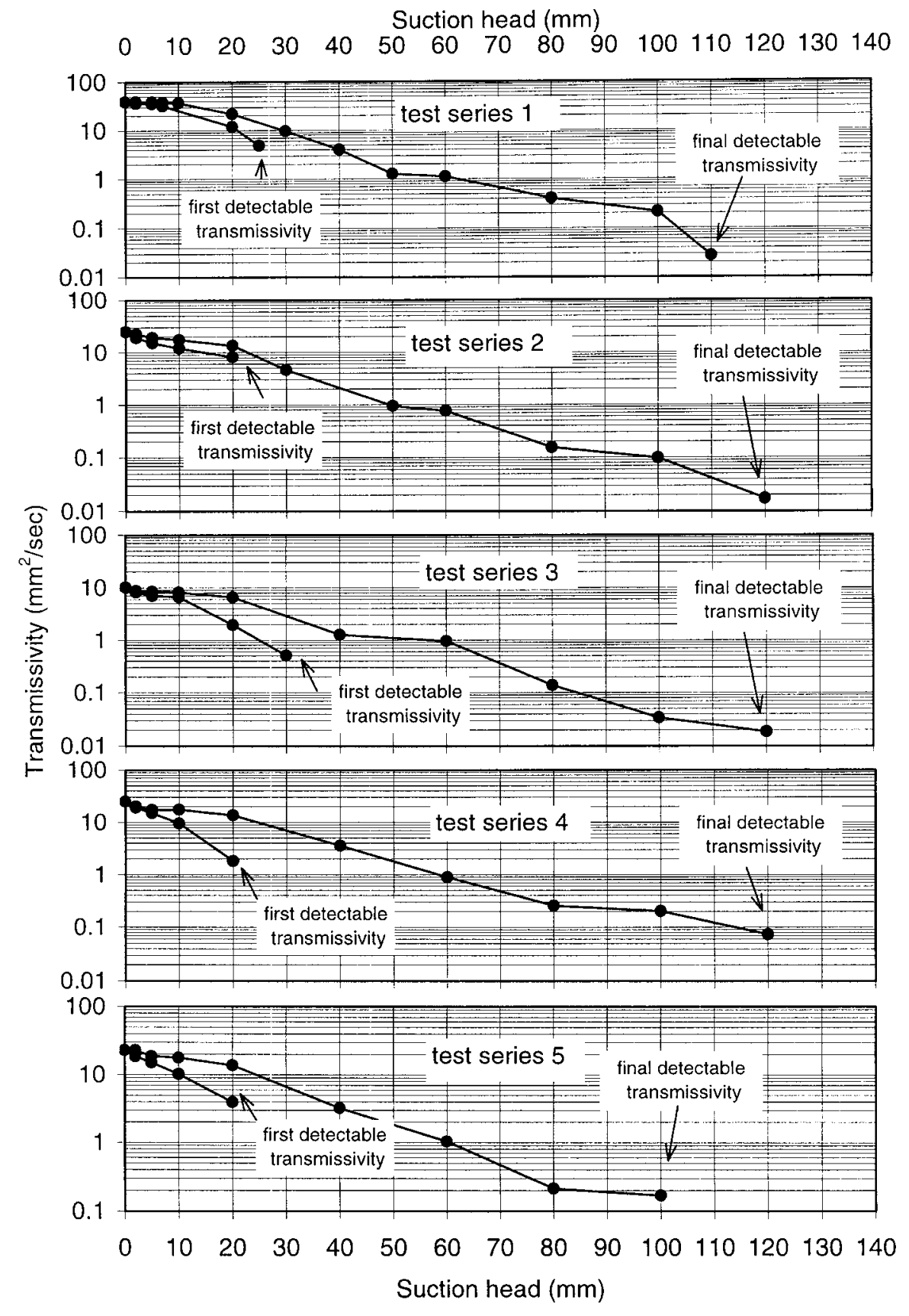

FIG. 5-Data from five test series. 
an order of magnitude. During drying, both the water content and transmissivity of the geotextile remain at greater values compared to the values obtained during wetting. These results suggest that these nonwoven geotextiles will wet and become transmissive under suction, but not until the suction in the adjacent soil is reduced to about $30 \mathrm{~mm}$.

\section{Suction Head Measurements}

Measurements made during the equilibrium portion of the tests confirmed that the suction heads within the geotextile were consistent with the platform height. Of the 51 equilibrium suction head measurements that were made during the equilibrium stage of the test under various conditions (platform height, normal pressure, wetting and drying path), 43 were identical to the imposed platform height, and the remainder were within $1 \mathrm{~mm}$.

The suction heads measured during the conduct of the flow portion of the transmissivity test compared well with those calculated assuming the transmissivity is constant along the length of the geo- textile. As an example, measured and calculated suction heads from the drying portion of test series 5 are given in Fig. 6. Consistent with the calculated values, the greater the platform height, the greater the variation in suction head along the geotextile. Further, these results confirm that the suction head variations along the geotextile are relatively small (less than $10 \%$ of the mean suction head in the geotextile). The good comparison between the measured and calculated suction heads and the relatively small variation along the length of the geotextile for these test conditions substantiate the assumption of a constant transmissivity and the use of Eq 3 to interpret the test data.

\section{Effect of Gradient}

The calculation of transmissivity (Eq 3) assumes that the transmissivity is linearly related to the flow rate by means of the gradient. This assumption can be evaluated by comparing test series under different gradients and similar normal pressures (Test Series 3, 4, and 5, given in Fig. 7). With the exception of data

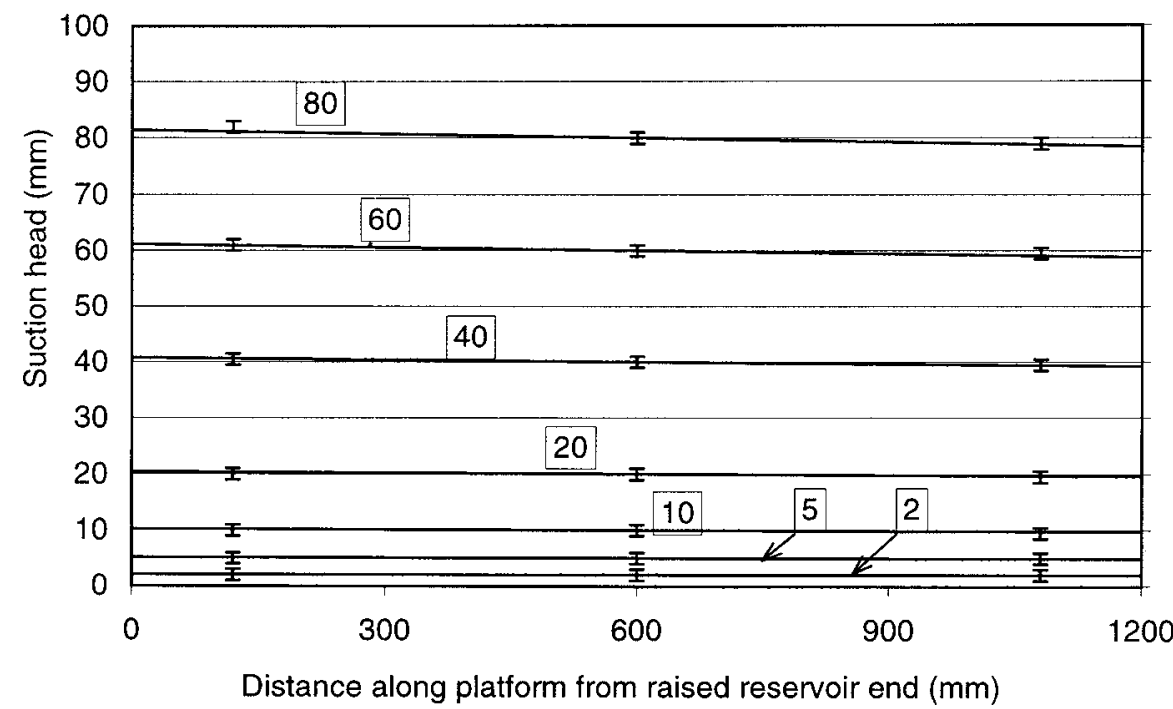

FIG. 6-Measured (I symbols) and calculated (solid line) suction values along geotextile's length from Test Series 5 drying path tests. Boxed numbers are the imposed platform heights.

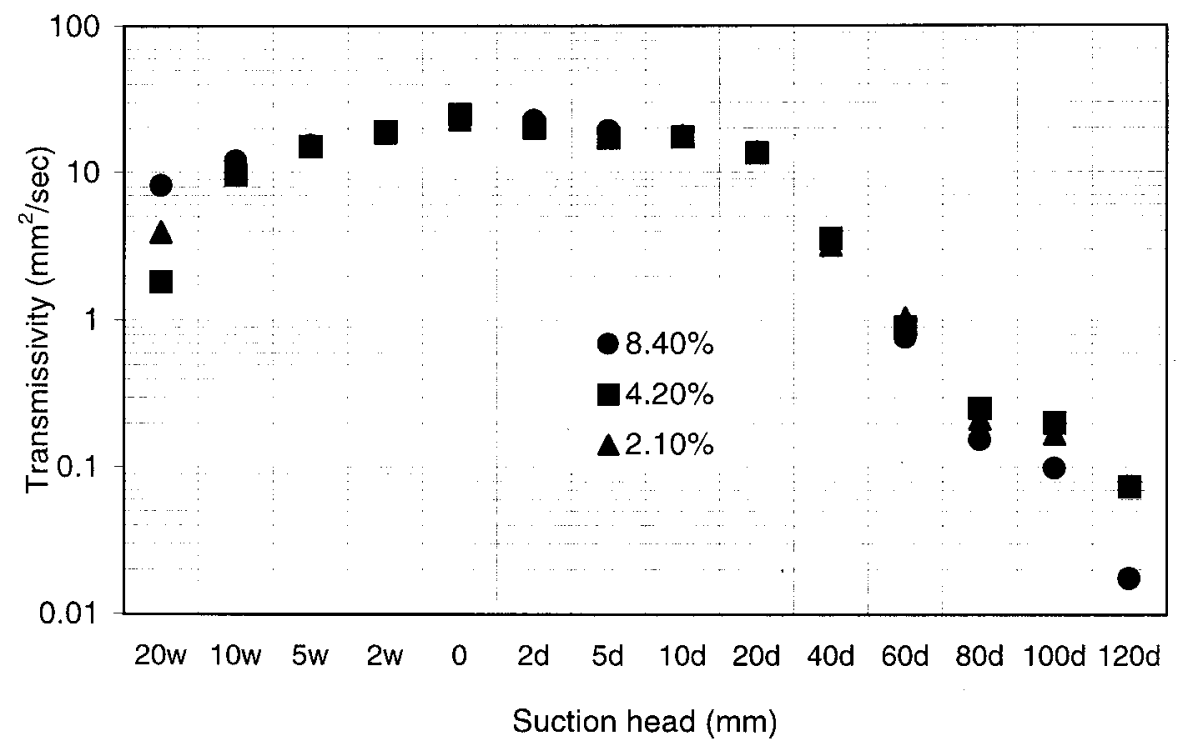

FIG. 7-Data from tests at three gradients with same normal pressure (Test Series 3, 4, and 5). Wetting and drying path suction heads are designated by " $w$ " and " $d$ ", respectively. 


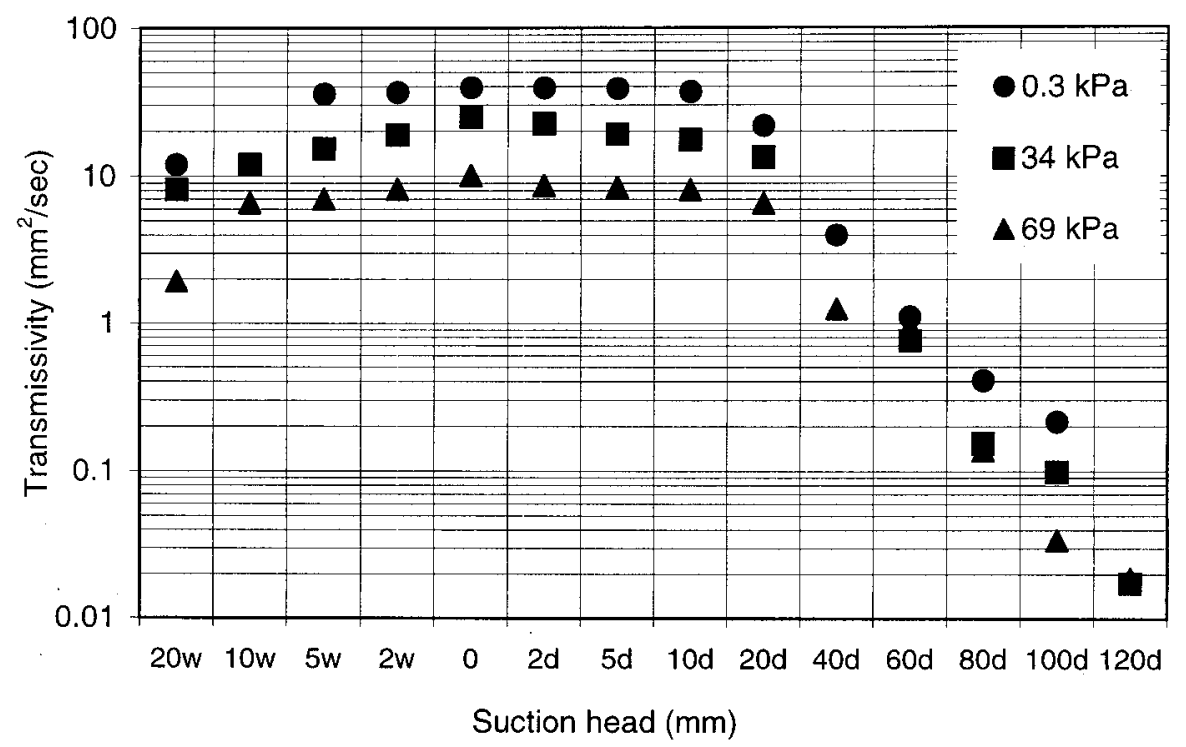

FIG. 8-Data from tests at three normal pressures with same gradient (Test Series 1, 2 and 3). Wetting and drying path suction heads are designated by " $w$ " and " $d$ ", respectively.

obtained at the initial and final suction heads, the transmissivities determined from tests at different gradients are quite close to one another. Over the range of $10 \mathrm{~mm}$ wetting to $60 \mathrm{~mm}$ drying, the transmissivities at a particular suction head are within about $10 \%$ of one another. These results demonstrate that the calculated transmissivity is independent of the imposed gradient, and substantiates the use of Eq 3 to calculate transmissivity. These results also suggest that the transmissivities are repeatable, bearing in mind each test series was conducted with a different geotextile specimen in addition to a different gradient.

\section{Effect of Normal Pressure}

Results from test series at three different values of normal pressure and similar gradient are given in Fig. 8. These results reveal that transmissivity decreased as the normal pressure was increased for all values of suction head, and are consistent with the conceptual model of larger pores being compressed as the normal pressure is increased. There was measurable transmissivity at $120 \mathrm{~mm}$ of suction head during drying for the tests at 35 and $69 \mathrm{kPa}$, whereas there was no measurable transmissivity at this suction head for the test at $0.3 \mathrm{kPa}$ normal pressure. This may be a result of the smaller pores in the geotextiles under appreciable normal pressure stress remaining transmissive, whereas at the lowest pressure the pores are not as small, and consequently are nonconductive at this value of suction head.

\section{Potential Bypass Leakage and the Influence of Platform Materials}

Tests were conducted to address potential bypass leakage and the influence of the platform materials in contact with the geotextile. These measurements were conducted under a normal pressure of $0.3 \mathrm{kPa}$, a gradient of about 0.07 , and suctions of 0,20 , and 50 $\mathrm{mm}$ during drying. The potential for bypass leakage was assessed by testing a geotextile specimen that was sealed in the permeameter with silicone sealant along the side edges. To evaluate the influence of the platform material in contact with the geotextile
TABLE 2-Effect of modifications to baseline conditions on transmissivity.

\begin{tabular}{lcc}
\hline $\begin{array}{c}\text { Modification of Baseline } \\
\text { Test Condition }\end{array}$ & $\begin{array}{c}\text { Suction } \\
\text { Head, mm }\end{array}$ & $\begin{array}{c}\text { Difference in Transmissivity } \\
\text { with Baseline Condition, \% }\end{array}$ \\
\hline Sealed edges & 0 & +2 \\
Sealed edges & 20 & +3 \\
Sealed edges & 50 & -6 \\
Rubber sheets & 0 & +5 \\
Rubber sheets & 20 & +16 \\
Rubber sheets & 50 & -6 \\
\hline
\end{tabular}

specimen, a test was conducted with rubber sheets on top and bottom of the geotextile, consistent with the suggestion in the test standard for measuring saturated transmissivity (ASTM D 4716). Finally, a test was conducted under the baseline conditions consistent with the previous measurements reported in the paper (no sealant, no rubber sheets).

These test results are summarized in Table 2. Sealing the geotextile edges did not have an appreciable effect on the measured transmissivities, with all of the measurements within $10 \%$ of the baseline conditions. The use of the rubber sheets did not result in substantially different transmissivities compared to the baseline condition. This result does not mean that transmissivities are always unaffected by adjacent material. In particular, adjacent soil that penetrates into a geotextile would be expected to affect the measured transmissivities. This is an area of future investigation.

\section{Conclusions}

A permeameter has been developed that is capable of measuring transmissivity of geotextiles while experiencing negative water pressures or suctions. The permeameter permits the measurement of flow through the geotextile under a nearly constant value of suction head. Normal pressures up to $240 \mathrm{kPa}$ and gradients in excess of $10 \%$ can be applied to the geotextiles during flow testing. Suction heads along the length of the geotextile can be monitored 
during testing. Transmissivities were calculated using a steadystate solution.

Tests were conducted under three normal pressures $(0.3,34$, and $69 \mathrm{kPa})$ and three gradients $(8.4,4.2$, and $2.1 \%)$. During initial wetting, the geotextiles are nonconductive until the suction head was reduced to about $25 \mathrm{~mm}$. The transmissivity increased by about an order of magnitude as they were wetted to near zero suction head. The geotextiles remain transmissive to beyond 100 $\mathrm{mm}$, well beyond the suction head at which they initially became transmissive.

During these tests, the measured suction heads within the geotextile were consistent with theory and confirmed the method of calculating transmissivity. The calculated transmissivities were found to be independent of the gradient. The transmissivities at all values of suction head decreased with increasing normal pressure applied to the geotextile.

\section{References}

Henry, K. S. and Holtz, R. D., 1997, "Capillary Rise of Water in Geotextiles," Proceedings, International Symposium on Ground Freezing and Frost Action in Soils, S. Knutsson, Ed., Luleå, Sweden, 15-17 April, pp. 227-233.
Henry, K. S. and Stormont, J. C., 2000, "Geocomposite Capillary Barrier Drain,' United States Patent 6,153,653, November 28, 2000.

Koerner, R. M., 1994, Designing with Geosynthetics, Prentice Hall, Englewood Cliffs, NJ.

Stormont, J. C., Henry, K. S., and Evans, T. M., 1997, "Water Retention Functions of Four Non-woven Polypropylene Geotextiles," Geosynthetics International, Vol. 4, No. 6, pp. 661-672.

Stormont, J. C. and Stockton, T. B., 2000, "Preventing Positive Pore Water Pressures with a Geocomposite Capillary Barrier Drain," Testing and Performance of Geosynthetics in Subsurface Drainage, ASTM STP 1390, J. B. Goddard, L. D. Suits, and J. S. Baldwin, Eds., American Society for Testing and Materials, West Conshohocken, PA, pp. 15-31.

Stormont, J. C. and Morris, C. E., 2000, "Characterization of Unsaturated Nonwoven Geotextiles," Advances in Unsaturated Geotechnics, C. D. Shackelford, S. L. Huston, and N.-Y. Chang, Eds., Geotechnical Special Publication 99, American Society of Civil Engineers, Reston, VA, pp. 153-164.

Zerfass, K.-Ch., 1986, "Syphoning Effect of Geotextiles," Third International Conference of Geotextiles, Vienna, Austria, pp. 1197-1202. 